\title{
Gómez Suárez, Águeda; Pérez Freire, Silvia y Verdugo Matés, Rosa María (2015): El putero español. Quiénes son y qué buscan los clientes de prostitución. Madrid: Catarata. 192 pp. ISBN: 978-84- 9097-003-4.
}

Esta obra es fruto de la investigación del proyecto: "Consumo de prostitución en España: clientes y mujeres", financiado por el Instituto de la Mujer de España (2011-2013). Una de sus pretensiones más clara es la de aportar datos y reflexiones al debate aún vigente sobre el hecho, no sólo económico y legal, sino social y humanitario de la prostitución en España. La obra, que aborda una realidad compleja y cuánto menos polémica, no sólo trata de realizar un perfil de la trabajadora del sexo y del usuario, así como un mapa de los minifundios y latifundios del mercado de la prostitución en España, sino que también ahonda en las motivaciones, críticas y visión que tienen las mujeres y los usuarios en la prostitución española y el problema sociológico que se plantea: cómo la precarización y la explotación se ve cada vez como un hecho más normal.

El libro se divide en siete capítulos haciendo un recorrido lógico por el problema y la temática a estudio. El primer capítulo titulado "Aproximándonos a la industria del sexo" comienza con una introducción general basada en diferentes estudios a nivel internacional y nacional sobre la prostitución, se especifica y caracteriza la industria del sexo en España y culmina explicando el porqué de estudiar el fenómeno de la prostitución en España desde la perspectiva del cliente. Solo el $1 \%$ de los estudios e investigaciones se centran en el cliente, pero en ninguno de los estudios realizados se ha profundizado sobre los motivos de la demanda del sexo de pago, algo que se pretende llevar a cabo a lo largo de esta obra basada en la investigación anteriormente citada.

El segundo capítulo "Lo que se sabe sobre el cliente" se inicia con un recorrido científico por las investigaciones internacionales, abordándose los antecedentes a nivel nacional e internacional sobre los clientes de sexo de pago. Este capítulo termina reflexionando sobre cómo de todas las investigaciones analizadas se deduce que el consumo de sexo de pago por parte de los varones deriva de una manera de comprender la masculinidad: el "ser hombre". Los valores tradicionales del varón -la paternidad responsable y el rol de protector y proveedor de la familia- han cambiado, pues hoy la masculinidad y la virilidad se construyen mediante una "compulsiva vida sexual" de la que presumir ante los demás pares masculinos.

El capítulo tercero cuyo título "minifundios y latifundios de la industria del sexo" se centra en describir la metodología y el trabajo de campo realizado en la investigación. El trabajo de campo se realizó en las siguiente Comunidades Autónomas: Andalucía, Aragón, Castilla y León, Cataluña, Comunidad Valenciana, Galicia, Comunidad de Madrid, País Vasco y Principado de Asturias. En este capítulo explica cómo la industria sexual adopta un modelo similar al de la distribución de la propiedad en las distintas regiones, diferenciándose los minifundios en el centro y noroeste de los latifundios en el sur y este peninsular. Los minifundios -Aragón, Castilla y León, Galicia y Asturias- muestran un panorama de la prostitución desplegada en clubs de carretera de pequeño y mediano tamaño, cerca de pequeños municipios o en las zonas industriales de la periferia urbana, algunos integrados en el hábitat urbano. Pequeños negocios que pertenecen en su mayoría a un dueño autóctono y que posee un número reducido de clubs en la localidad y alrededores. La gestión de estos negocios se lleva a cabo de idéntica forma a la de una empresa familiar donde los empleados son vecinos del lugar y el dueño es el que se encarga del reclutamiento de las mujeres en los países emisores. Esto no significa que en ocasiones el dueño no esté vinculado a redes internacionales de tráfico y trata de personas. La mayoría de estos clubs suelen estar integrados en la vida municipal e incluso llegan a ser patrocinadores de clubs de fútbol u otras actividades locales. Por el contrario, el latifundismo -sur y este de España- responde a un modelo de zonas turísticas en la que el macroclub, los macro-chalets o la distribución en cadena a través de pisos pertenecientes a una o varias cadenas de negocios de alterne es el común denominador. Éste tipo de perfil latifundista suele ubicarse en la periferia de las grandes capitales de provincia y poseen un sistema de empleo más complejo, formado por empleados extranjeros y con una mayor diversidad en país de origen de las mujeres en prostitución.

El cuarto capítulo "mujeres en la industria del sexo" comienza analizando los componentes contextuales y estructurales de la industria sexual y del hecho prostitucional, para ello se hace referencia a un estudio de caso basado en la operación policial "Operación carioca" (Lugo). Posteriormente se analizan los discursos de las mujeres que ejercen la prostitución con el fin de poder conocer los motivos que las empujan a ejercerla, las condiciones a las que se ven sometidas y las opiniones que tienen de sus clientes. En definitiva analizar el papel del protagonista principal de este fenómeno social masivo: las mujeres en prostitución. 
El siguiente capítulo: "Cómo ser un hombre", hace hincapié en las nuevas masculinidades, en su estudio y análisis desde diferentes perspectivas y puntos de vista, entre los que se encuentra el enfoque psicobiologista -el deseo sexual es una necesidad orgánica básica-, el enfoque funcionalista -el papel social- y el enfoque constructivista -el género es socialmente construido y no biológicamente determinado-. Con este recorrido por las teorías de la masculinidad se pretende resaltar los cambios en el rol masculino, íntimamente relacionados con el consumo de sexo de pago por parte de los hombres. El perfil sociológico analizado en los clientes de prostitución en este estudio es muy amplio, abarcando todas las edades, niveles educativos y de formación, diferentes profesiones, estados civiles y nivel económico en una clasificación que resulta muy amplia.

El eje central del estudio descansa en el sexto capítulo, "Tipología de puteros españoles", donde se aborda el estudio de los clientes y las tipologías derivadas de las narraciones elaboradas por ellos en relación a los marcos narrativos de sus discursos. Tras el análisis discursivo de las entrevistas realizadas a clientes realizan una tipología de clientes: a) el cliente misógino que considera la existencia de este tipo de servicios algo normal y necesario, pagan servicios de prostitución porque es la única forma de poder conseguir una relación sexual y comparten una visión extremadamente misógina de todas las mujeres. b) El cliente consumidor que se trata generalmente de un perfil de varón joven, con un discurso no sexista, formados y que comparten una ética hedonista de consumo. Estos piensan que tanto hombres como mujeres únicamente buscan sexo en sus relaciones y eso lo trasladan a su posición como consumidor. Este perfil permite introducir en la obra el término McSexo -sexo rápido, frugal, de escasa calidad y sin compromiso-. c) El cliente amigo es el tipo de cliente en el que se enmascara aquellos hombres que adoptan una actitud amable y paternal frente al sexo de pago. Es el cliente que empatiza y humaniza a las mujeres que trabajan en prostitución. La opinión de este tipo de cliente sobre las prostitutas es que ejercen la prostitución porque no han tenido otra alternativa, actitud que los lleva en ocasiones a establecer lazos afectivos. d) El cliente crítico es el perfil menos habitual. Reconoce la diferencia de géneros y las injusticias que sufren las mujeres en la sociedad, considerando que las mujeres en prostitución son uno de los colectivos más vulnerables de la sociedad. Este tipo de cliente opina que las mujeres ejercen la prostitución por necesidad o por coacción como víctimas de las mafias. El único punto en común que se encuentra en el estudio entre todos los tipos de clientes es la práctica grupal o social que es vista, en ocasiones, como un rito de iniciación, o bien para hacerse hombres o bien para cerrar negocios o celebración. El capítulo séptimo "reflexiones de técnicas y expertas" trata de analizar las diferentes posturas políticas y críticas en torno a la prostitución y a otros actores implicados.

La última parte del libro muestra las reflexiones sobre los resultados del estudio, exponiéndose las principales conclusiones y recomendaciones entre las que se propone la creación de un programa marco de carácter nacional que intente impulsar conductas humanas inspiradas en valores democráticos, de respeto, convivencia, justicia, solidaridad e igualdad. Un programa que, según las autoras, debería estar destinado al colectivo masculino, encaminado a acabar con todo tipo de actitud sexista, homófoba y violenta. Debería generar situaciones de empatía con las mujeres en general y, en particular, con el colectivo de mujeres en prostitución. Un programa que se estructuraría en diversas actuaciones en los ámbitos administrativos, legislativos, educativos y de comunicación de masas. En definitiva este libro resume la investigación "Consumo de prostitución en España: clientes y mujeres" sin ahondar demasiado en discursos éticos, legales, morales y feministas. Dejan la puerta abierta a la elaboración de una nueva epistemología sobre el género y la sexualidad basándose en el programa marco.

Almudena García Manso Universidad Rey Juan Carlos, España almudena.manso@urjc.es

Recibida: 19-2-2015 Aceptada: 25-3-2015 